\title{
AVTOPORTRETNI MOTIV UMETNICE S KNJIGO V ROKI
}

Ključne besede: avtoportret, motiv knjige, subjektiviteta, renesančna slikarka, Sofonisba Anguissola

\section{Uvod}

Atribut knjige bo v pričujočem besedilu obravnavan kot pomemben emancipacijski motiv avtoportretistk, prek katerega so lahko umetnice izražale težnjo po predstavitvi lastne izobraženosti in vzpostavitvi lastne subjektivitete. V klasičnem avtoportretnem žanru so se nekatere avtorice že od renesanse naprej upodabljale kot avtonomni subjekti ob določenih aktivnostih, na primer med slikanjem s slikarskimi pripomočki, pri branju s knjigo $v$ roki ali ob glasbilu. Ikonografski motiv bralke s knjigo naj bi še posebej v preteklosti simboliziral učenost, izobraženost ali razgledanost žensk. V obdobjih, ko so se lahko šolale le redke posameznice, je omenjeni motiv za umetnice vsekakor predstavljal pomemben osvobajajoč izziv. V času, ko so umetniki ženske raje kot izobraženke s knjigo v rokah upodabljali kot gole zapeljivke, je bilo še toliko pomembneje, da so si nekatere umetnice ob podobah ženskih figur s knjigami prizadevale poudariti vlogo ženske kot bralke. Če so podobe avtorice s knjigo po eni strani reprezentirale simbol učenosti in modrosti žensk, je po drugi strani omenjeni motiv lahko služil tudi kot mesto avtoričinega podpisa, kar bo natančneje obravnavano ob delih renesančne slikarke Sofonisbe Anguissola (ok. 1532-1625). ${ }^{1}$

1 Podatki o Sofonisbi Anguissola so zbrani iz naslednjih virov: Chadwick (1996, 77-86); Parker in Pollock (1981, 84-88); Petersen in Wilson (1976, 25-26); Slatkin (1985, 68-72). Več 
Avtoportret se je skozi zgodovino pri prevpraševanju in vzpostavljanju lastnih subjektnih pozicij izkazal kot najprimernejša in najdostopnejša umetniška oblika. ${ }^{2}$ Izpostavitev sebe kot avtonomnega subjekta je bila na umetniških delih za ženske še posebej pomembna v obdobjih, ko jim likovne umetnosti večinoma niso bile dostopne kot profesionalne dejavnosti. Umetnice so se tako že od renesanse naprej upodabljale v aktivnih vlogah slikark, glasbenic ali bralk. Na samopodobah so lastno likovno znanje, sposobnosti in veščine razkrivale prek atributov, kakršni so čopič, glasbilo ali knjiga, ki so pri ustvarjanju kreativne identitete žensk predstavljali pomembne kulturne kode. Na tem mestu se bomo osredotočili predvsem na klasične avtoportrete, ki so izobraženost oziroma učenost žensk razkrivali ob motivu knjige. Vse omenjene teme je v avtoportretno umetnost vpeljala že Sofonisba Anguissola, ki ji bo zato na tem mestu posvečeno nekoliko več pozornosti. Pri tem se zastavlja vprašanje, zakaj se je prva umetnica, ki se je s slikarstvom ukvarjala profesionalno, na svojih avtoportretih pogosteje upodabljala s knjigo ali ob glasbilu kot s čopičem in drugimi slikarskimi pripomočki.

\section{Sofonisba Anguissola - prva profesionalna slikarka}

Pred analizo konkretnih del ene prvih slikark, ki se je upodobila s knjigo v roki, si najprej poglejmo nekaj okoliščin iz življenja in predvsem obdobja, v katerem je ustvarjala. ${ }^{3}$ Renesančna slikarka iz Cremone je bila vsekakor

o njenem avtoportretnem opusu gl. Borzello (1998, 36-49).

2 Določena zavest $\mathrm{v}$ zvezi $\mathrm{z}$ lastno subjektiviteto žensk, ki se je dokončno vzpostavila s sodobno feministično teorijo in umetnostjo, je imela svoje zametke že pri umetnicah preteklosti, še posebej pri nekaterih izjemnih slikarkah, med katere sodi tudi Sofonisba Anguissola iz renesanse. Ob interpretacijah del iz starejših zgodovinskih obdobij velja sicer opozoriti na previdnost pri uporabi sodobnih terminov in konceptov, ki se v kontekstu avtoportretnega raziskovanja nanašajo na primer na prevpraševanja lastnih identitetnih in subjektivitetnih pozicij.

3 O življenju Sofonisbe Anguissola ni veliko znanega. Biografije so v tedanjem času pisali le moški, ki so jih povečini zanimala življenja slavnih mož. Kot prva v družbi priznana slikarka je verjetno živela zanimivo in gotovo precej drugače od večine žensk njene dobe. Po drugi strani lahko prav odsotnost natančnejših biografskih podatkov omogoča, da lahko brez mitologiziranja strokovno obravnavamo predvsem samo slikarkino delo. 
ena izmed privilegiranih žensk svojega časa in ena redkih, ki je bila deležna izobrazbe. ${ }^{4}$ Slikanja se je skupaj s sestro Eleno tri leta učila pri Bernardinu Campiju. ${ }^{5}$ Sofonisba Anguissola, katere ime še vedno ni najbolj znano niti znotraj umetnostnozgodovinske stroke, je bila za časa svojega življenja zelo spoštovana. Povabljena je bila na španski dvor Filipa II., kjer je med letoma 1559 in 1573 delovala kot dvorna portretistka. Bila je torej prva slikarka, ki je doživela mednarodno slavo. ${ }^{6}$ Kot izjemna portretistka je s svojo izvirnostjo bistveno vplivala na razvoj italijanske portretne in avtoportretne umetnosti. S svojim delom je postala zgled številnim kasnejšim umetnicam, saj je njen primer pokazal, da se lahko s slikarstvom v družbi profesionalno ukvarjajo tudi ženske (prim. Chadwick, 1996, 78; Parker in Pollock, 1981, 84).

Lahko bi rekli, da pomeni Sofonisba Anguissola na področju likovne umetnosti začetno figuro genealogije ženskih slikark v podobnem kontekstu, kot predstavlja srednjeveška pisateljica Christine de Pizan ključno figuro za začetek matrilinearne genealogije vednosti. Zaradi motivov, ki jih je renesančna slikarka vpeljala $v$ avtoportretno umetnost, jo lahko označimo za predhodnico sodobnih feminističnih umetnic. Kljub nedvomni kakovosti njenih del, novim žanrom, ki jih je vpeljala v portretno in avtoportretno

4 Rojena je bila v ugledni in premožni aristokratski družini. Njen oče, Amilcaro Anguissola, vdovec in plemič z veliko posluha za humanizem, se je zavedal, da je izobrazba njegovih hčera prav tako pomembna kot izobrazba njegovih sinov. Zato se je odločil, da bo vseh svojih sedem otrok enakopravno izobrazil v skladu s tedanjimi porajajočimi se humanističnimi ideali, ki so spodbujali tudi izobraževanje žensk. Sofonisba Anguissola je bila tako skupaj s svojimi sestrami vzgajana $\mathrm{v}$ skladu $\mathrm{z}$ renesančnim idealom, po katerem naj bi plemenite dame obvladovale tako glasbeno kot tudi slikarsko umetnost.

5 Sofonisba Anguissola se je nedvomno dobro zavedala privilegija lastne izobrazbe in še posebej pomembnosti lastnega slikarskega znanja, ki ga je prejela od svojega učitelja Bernardina Campija. To je mogoče razbrati tudi z njenega avtoportreta Bernardino Campi slika Sofonisbo Anguissola (ok. 1550), ki je očitno nastal kot poklon in zahvala za dobo učenja. Avtorica slike je svoj lastni portret naslikala tako, da je videti, kot da nastaja izpod rok slikarja, pri katerem se je izobraževala.

6 Kot je navedla Whitney Chadwick, je španski dvor na njeno delo opozoril guverner iz Milana, s katerim se je posvetoval vojvoda iz Albe. V Španijo je bila leta 1559 pospremljena z veliko slovesnostjo. Tam je do leta 1573, v času kraljic Isabele Valoiške in Anne Avstrijske, delovala kot dvorna slikarka in dvorna dama. Na dvoru je bila plačana na običajen način, $\mathrm{s}$ plačo dvorne dame, leta 1561 pa je prejela tudi doživljenjsko pokojnino dvestotih dukatov, izplačanih njenemu očetu (Chadwick, 1996, 79). 
umetnost, ter kljub vsej slavi, ki je je bila deležna za časa življenja, kasneje ni bila vključena $\mathrm{v}$ umetnostnozgodovinski kanon. Umetnostnih zgodovinarjev njena dela očitno niso zanimala do te mere, da bi jih objektivno ovrednotili in jim pripisali mesto, ki jim v zgodovini portretne umetnosti vsekakor pripada. Sofonisba Anguissola je tako ostala dokaj neznana avtorica vse do feminističnih odkrivanj spregledanih umetnic v drugi polovici 20. stoletja. ${ }^{7} \mathrm{Na}$ tem mestu se želim izogniti tako tarnanju nad položajem prezrtih in neupoštevanih umetnic preteklosti kot tudi njihovemu pretiranemu poveličevanju. Čeprav slikarstva Sofonisbe Anguissola ne nameravam izenačevati z delom njenega precej bolj znanega sodobnika Tiziana, ${ }^{8}$ pa primerjave v kontekstu spolnih razlik tedanje dobe vendarle niso povsem odveč. Kljub vsem omejitvam, ki jih je bila Sofonisba Anguissola pri slikarskem ustvarjanju deležna zaradi svojega spola, je že v tistem času zablestela na področjih, ki se jim je kot ženska vendarle lahko posvečala. To je bilo predvsem portretno slikarstvo. V portretnem žanru je postala prava mojstrica in velja za utemeljiteljico domačih žanrskih prizorov. Najprej je slikala predvsem svoje sestre in brate, s katerimi je bila obkrožena doma, in pri tem razvila kompozicijo skupinskega portreta $\mathrm{v}$ domačem okolju (Petersen in Wilson, 1976, 25), kasneje pa je v španskem obdobju zablestela tudi kot izjemna dvorna portretistka. Pri tem ne gre zanemariti, da so ne-

7 Prva monografija o renesančni slikarki je izšla šele leta 1987, njena prva in glavna retrospektivna razstava pa je bila postavljena leta 1994. Kot omenja Whitney Chadwick, so šele sodobne raziskave pripomogle $\mathrm{k}$ razjasnitvi Anguissolinega naturalizma in njene inovativnosti pri pionirskih žanrskih prizorih, njene prepoznavnosti v zvezi s spojem med italijanskim in španskim portretiranjem 16. stoletja ter njenim vplivom na kasnejši italijanski avtoportret (Chadwick, 1996, 78).

8 Whitney Chadwick je zapisala, da je bila Sofonisba Anguissola podobno kot mnogo kasnejših umetnic podvržena različnim kritičnim ocenam, od pozitivnih, kakršna je bila Baldinuccijeva izjava v 17. stoletju, da je bila v portretiranju enakovredna Tizianu, do popolne odklonitve oziroma očitanja glede pomanjkanja veščine v risanju s strani Sydney Freedberg leta 1971. Njeno razmeroma pomanjkljivo šolanje se je primerjalo z izobrazbo glavnih moških umetnikov njenega časa. Velja poudariti, da je v primerjavi z njenimi tremi leti privatnih inštrukcij v ateljejih Bernardina Campija in Bernardina Gattija večina moških takrat opravila štiri leta šolanja $v$ delavnicah. Še vedno ostaja edina ženska svoje dobe, ki ji pripisujemo zmožnost navdihnjenja podobe z življenjem. Njeno delo je bilo s strani njenih sodobnikov spoštovano in razumljeno. In kot je v zvezi s tem še zapisala Whitney Chadwick: »Čeprav se ne more primerjati s Tizianom, pa mora biti njeno delo za vsakogar, ki poskuša razumeti portretno umetnost 16. stoletja, vendarle precej zanimivo" (Chadwick, 1996, 78). 
katere njene portrete kopirali že slikarji tistega časa ${ }^{9}$ in da so bila določena njena dela kasneje pripisana Tizianu in drugim moškim umetnikom. ${ }^{10}$

\section{Avtoportretni opus Sofonisbe Anguissola}

V nadaljevanju me bo še posebej zanimal slikarkin izjemen avtoportretni opus, ki ga je ustvarjala od najstniških let do pozne starosti. Ohranjenih naj bi bilo najmanj dvanajst njenih avtoportretov. Slikala se je na najrazličnejše načine in $\mathrm{z}$ raznovrstnimi atributi, prek katerih je poudarjala svoje družinsko plemiško poreklo ter pripadnost kulturni eliti, hkrati pa tudi svoje znanje oziroma določeno vrsto izobrazbe, na primer obvladovanje glasbene in slikarske umetnosti. Pravzaprav se je ob glasbilu ali s knjigo v rokah upodobila večkrat kot $s$ čopičem ali paleto, ki sta poudarjala njeno profesionalno vlogo slikarke. Pri tem velja spomniti, da se je v obdobju renesanse slikarstvo šele počasi osvobajalo obrtniškega značaja in da je bilo za omikana dekleta obvladovanje glasbene umetnosti precej bolj cenjeno kot slikarsko znanje. Prav zato se bom v nadaljevanju ob analizi posameznih motivnih sklopov, ki jih je Sofonisba Anguissola vpeljala v avtoportretno slikarstvo, osredotočila predvsem na lastne podobe s knjigo $\mathrm{v}$ rokah.

Sofonisba Anguissola se je $\mathrm{z}$ avtoportretno umetnostjo začela ukvarjati ob samih začetkih tega žanra, ko tudi veliko moških umetnikov še ni slikalo samostojnih lastnih portretov. Gre namreč za čas, ko se je avtoportret šele začenjal razvijati. Tedaj se je postopoma začela oblikovati tudi vloga umetnika, kar je veljalo predvsem za moške. Do renesanse so bili slikarji in kiparji pojmovani kot cehovski obrtniki, ki so likovna dela izdelovali v

9 Whitney Chadwick je omenjala probleme, ki so obkrožali Anguissolino delo v španskem obdobju. Na dvoru so namreč lahko naročili številne kopije končanih slik kateregakoli od njenih portretov. Ko je njen Portret Dona Carlosa leta 1568 razveselil princa, je ta naročil trinajst kopij za kraljevski dvor pri slikarju Alfonsu Sanchezu Coellu (Chadwick, 1996, 79).

10 Med umetnostnimi zbiralci je ostala Sofonisba Anguissola cenjena še v 17. in 18. stoletju. Nato je postala usoda njenega slikarstva podobna usodi del večine žensk v zgodovini. $\mathrm{V}$ 19. stoletju so nanjo pozabili in je bilo, kot poroča Whitney Chadwick, veliko njenih del pripisano moškim umetnikom, na primer Alfonsu Sanchezu Coellu, Giovanniju Moroniju in Tizianu (Chadwick, 1996, 78). 
obrtniških delavnicah. V status umetnika so bili povzdignjeni na prehodu iz srednjega veka $\mathrm{v}$ renesanso, torej v obdobju, ko se je popolnoma spremenil sam status likovne umetnosti, ki se je tedaj iz obrti povzpela med artes liberales (Mikuž, 1997, 83). Takrat naj bi liberalna ali svobodomiselna umetnost postala bolj miselno oziroma razumsko naravnana, s čimer naj bi se začela razlikovati od predhodnih veščin, po Leonardu da Vinciju pa naj bi bila celo božje navdahnjena. Roszika Parker in Griselda Pollock sta poudarili, da so se umetniki v renesansi poskušali razlikovati od obrtnikov in ročnih izvrševalcev idej drugih ljudi: »Umetnik si je prizadeval za enakopraven status z intelektualcem, pokroviteljem, pisateljem, pesnikom, filozofom ali teologom. « Nov ideal umetnika naj bi se od obrtnika razlikoval $\mathrm{v}$ tem, da se je umetnik »zavedal svojih intelektualnih in kreativnih moči« (Parker in Pollock, 1981, 86). Za razliko od srednjeveških anonimnih cehovskih obrtnikov so postajali vse bolj ustvarjalni subjekti, samozavestni avtorji, ${ }^{11}$ ki so svoje slike začeli podpisovati (prim. Mikuž, 1997, 94; Borzello, 1998, 43). Pred tem se obrtniki, ki še niso bili pojmovani kot umetniki, na svoja dela niso podpisovali z imeni, temveč so nekateri svoje slike zaznamovali na zelo inovativne načine, na primer $\mathrm{z}$ lastno podobo. Luc Menaše je za prve samopodobe iz 15. stoletja zapisal, da so služile kot neke vrste podpisi namesto imen. Slikarji so se upodabljali v podrejenih, preoblečenih in asistenčnih avtoportretih, ki jih je avtor imenoval »umetnikov ponosni podpis«. Tako so se zaznamovali predvsem na svojih najpomembnejših stvaritvah, v Italiji v okviru velikih stenskih slikarij, v nizozemskih in nemških deželah pa na krilnih oltarjih (Menaše, 1962, 258). Sčasoma je slikarjevo oziroma kiparjevo delo postajalo vse bolj cenjeno kot umetniška in ne več kot obrtna dejavnost. $Z$ novim dojemanjem samih sebe se je med umetniki, kot je bilo že omenjeno, vzpostavila tudi določena mera samozavesti. V tem času so začeli nastajati prvi samostojni tabelni avtoportreti, ki so zamenjali predhodne asistenčne lastne podobe. Menaše je zato v splošnem razvoju evropskega umetniškega avtoportreta razločeval dve glavni

11 Izidor Cankar je opisal, kako se je v renesansi oblikovala nova umetniška osebnost v psihološkem in socialnem smislu: $V$ času renesanse iščejo dvori znamenitih umetnin, hočejo imeti slavne umetnike v svoji službi in umetnik raste medtem iz stanu veščega in spoštovanega rokodelca, kar je še bil skoraj do konca 15. stoletja, k socialni pomembnosti in k zavesti o lastni potrebnosti in kulturni važnosti« (Cankar, 1936, 28). 
obdobji, in sicer »čas kompozicijsko, ikonografsko in vsebinsko podrejenega, nesamostojnega avtoportreta in veliko, do današnjih dni segajočo dobo samostojnih lastnih podob« (Menaše, 1962, 154).

Avtoportretni opus Sofonisbe Anguissola vsekakor sodi med prave izjeme tedanjega časa, kar se v klasični umetnostni zgodovini vse do sodobnih feminističnih raziskovanj ni nikdar posebej poudarjalo. Kot je izpostavila Ann Sutherkland Harris, je Sofonisba Anguissola naslikala največ lastnih podob v obdobju med Dürerjem in Rembrandtom, poleg tega pa je bila tudi edinstvena $\mathrm{v}$ raznovrstnosti portretov (Chadwick, 1996, 78). Razen Dürerja sicer ni znano prav veliko avtorjev, ki bi se že tedaj upodabljali na samostojnih avtoportretih. Kot že rečeno, so se moški slikarji v tistem času slikali predvsem v sklopu različnih likov na večjih slikah z religioznimi, mitološkimi, zgodovinskimi in različnimi herojskimi motivi, tako da so svojo podobo umestili v sliko kot nekakšen avtorski podpis. V obliki asistenčnih lastnih podob se je tedaj navadno upodabljal tudi Tizian. Čeprav je svoj lik na večjih delih upodobil kar nekajkrat, pa ni ustvaril veliko samostojnih lastnih portretov. Znana naj bi bila le dva njegova neodvisna avtoportreta, ki ju je naslikal šele po svojem sedemdesetem letu. Ena njegovih redkih samostojnih lastnih podob je Avtoportret iz leta 1567, na katerem se je upodobil od strani, s čopičem, ki ga drži v desnici. ${ }^{12}$

Znano je, da so bile ženske zaradi omejenih možnosti izobraževanja in popolne nemožnosti upodabljanja človeškega telesa v žanru akta že v osnovi diskriminirane v smislu slikanja velikih mitoloških, bibličnih ali zgodovinskih tem. ${ }^{13} \mathrm{~V}$ obdobju, ko je lahko Sofonisba Anguissola slikala le portrete

12 Tizianov obraz je sicer mogoče prepoznati na različnih mladostnih in prvih zrelih delih. Kot omenja Zuffi, se je petindvajsetletni slikar na sliki Marija s svetim Ulfom in Brigito (ok. 1515) upodobil v svetnikovem obrazu (Zuffi, 1998, 22). Na sliki Sveti Marko na prestolu iz leta 1511 (Benetke, Santa Maria della Salute) se je naslikal na desni strani v ozadju, z dolgimi lasmi in temno brado (prav tam, 23). Na sliki Saloma (1516) predstavlja avtoportret odsekana glava Janeza Krstnika (prav tam, 28). Na Poliptihu Averoldijev, končanem med letoma 1520 in 1522, je mogoče Tizianov »zakriti« avtoportret prepoznati v obrazu »vstalega Kristusa, ki ga čudežni veter vzdiguje iz groba, da plahutajo oblačila in bandero«. Po potezah zelo spominja na obraz svetega Boštjana, ki je prav tako Tizianov »zakriti« avtoportret (prav tam, 45). Na enem svojih zadnjih večjih del z naslovom Pieta, ki je ob njegovi smrti leta $1576 \mathrm{v}$ nekaterih podrobnostih ostalo nedokončano, se je Tizian upodobil v figuri Nikodema, ko tik pred devetdesetim letom kleči pred mrtvim Kristusom in se, kot pravi Zuffi, do kraja razgalja (prav tam, 131).

13 Na diskriminacijski vidik v zvezi z nemožnostjo izobraževanja žensk na likovnih akademi- 
uglajenih dam ali resnobne lastne portrete, za katere je bilo problematično že, če se je na njih naslikala kot preveč nasmejana, so njeni moški kolegi začeli ne le razpravljati o lepoti in čutnosti, temveč tudi slikati konkretne erotične prizore. ${ }^{14}$ Renesančnih razprav o lepoti in erotiki v umetnosti so se tedaj v javnosti lahko udeleževali zgolj moški teoretiki in umetniki. ${ }^{15}$ Ženske, sicer le redke posameznice iz najelitnejšega družbenega sloja, so bile tedaj lahko vesele že, če jim je bila izobrazba sploh omogočena, čeprav seveda na zelo omejenih in točno določenih področjih. ${ }^{16} \mathrm{~V}$ času, ko so lah-

jah in onemogočanjem učenja risanja na golem modelu je v svojem znanem eseju »Zakaj ni bilo velikih umetnic?" prva opozorila Linda Nochlin $(2004,9)$.

$14 \mathrm{~V}$ slikarstvo 16. stoletja se je v skladu $\mathrm{z}$ neoplatonističnimi vplivi vrnilo antično poveličevanje erotične in estetske izkušnje. Whitney Chadwick je navedla pisce, ki so pisali o glavnih atributih ženske lepote. Eden takšnih je bil Angolo Firenzuola, avtor najbolj dovršene razprave o lepoti, izdani leta 1548 . Poudariti velja, da so se te nanašale predvsem na žensko lepoto oziroma na atribute ženske lepote. Avtorji so opisovali omikane dame z nežno svetlo poltjo, kodrastimi lasmi, temnimi očmi, dovršeno oblikovanimi obrvmi in zaobljenim telesom. Marsilio Ficino je v Theologia Platonica trdil, da fizična lepota vzburja dušo do kontemplacije o duhovni ali božanski lepoti. Vzporedno s poveličevanjem ženske lepote so slikarji na svojih slikah začeli upodabljati tudi bolj čutne ideale lepote. Ti so lepo prepoznavni ob lepoticah na številnih Tizianovih delih, med katerimi še posebej izstopa njegova slika Lepotica (La Bella) iz leta 1536 (Chadwick, 1996, 84).

15 Ali kot je zapisala Whitney Chadwick: »Sofonisbo Anguissola sta njen spol in starost ovirala pri sodelovanju v estetskem dialogu, ki se je vrtel okrog neoplatonističnih konceptov metaforičnega odnosa med slikanjem in lepoto, posvetnim in sublimnim, materialnim in božanskim. Vasari in drugi moški pisatelji so Sofonisbo Anguissola in njene sestre raje kot umetnice sprejeli kot čudesa narave, kar je še bolj razumljivo v kontekstu estetskih dialogov, ki so akt slikanja identificirali z moško umetniško seksualno zmožnostjo. Anguissola ni mogla uporabiti slikanja kot metafore za možno lepoto brez onečaščenja družbene vloge, v kateri je živela kot slikarka. Kot umetnica je bila prisotna v svetu vznemirjenja in užitka, vendar pa je bilo to možno le zato, ker je bila neporočena, s čimer je po drugi strani kršila naravne zakone. To je bila njena krepost, kar so poudarjali tako Anguissola kot njeni biografi« (Chadwick, 1996, 85).

16 Whitney Chadwick je poudarila, da renesančni humanistični ideali v zvezi z izobraževanjem žensk v praksi vendarle niso bili tako samoumevni: „Čeprav so humanistični misleci nedvomno branili enakopravnost pri izobraževanju hčera in sinov bogatih meščanov in plemičev, pa je bila v 15. stoletju praksa pošiljanja deklet v javne šole očitno prekinjena. Dekleta so prejela svojo izobrazbo, ki se je osredotočala na krščanske vrline in moralno učenje, prvenstveno doma ali v samostanu. Fantje so od domačega učenja napredovali k javnemu izobraževanju, organiziranemu okrog zadev skupnosti, medtem ko so bila dekleta vzgajana za poroko ali samostan. Javna izobrazba je bila sestavljena iz branja, pisanja in aritmetike s poudarkom na matematiki, ker so bili posli orientirani na florentinsko družbo« (Chadwick, 1996, 72). 
ko o vseh pomembnih temah razpravljali zgolj moški, je bila torej vloga žensk v umetnosti bolj ali manj zvedena predvsem na njihova telesa kot predmete, namenjene užitku. V estetskih dialogih so se pojavljale le kot objekti razprav. Prav tako so moški ženska telesa slikali predvsem kot lepe figure, namenjene gledalčevemu ugodju. Tizianova Lepotica ( La Bella), naslikana leta 1536, je prvi primer portreta, pri katerem identiteta upodobljenke kot posameznice ni bila pomembna, temveč je šlo za umetniško delo, ki je predstavljalo idealizirano ženskost (Chadwick, 1996, 84). Portretiranka, ki kar najbolj uteleša renesančni ideal ženske lepote, o kakršnem so pisali tedanji humanisti, je bila upodobljena kot alegorija lepote $\mathrm{z}$ nežno svetlo poltjo, $\mathrm{s}$ kodrastimi zlatimi lasmi in temnimi očmi, ki jih zaokrožajo elegantne obrvi. Lepoto njenega telesa poudarjajo še bogata brokatna obleka, umetelno spletena pričeska in izbrani nakit. Graciozna dama je prikazana kot polfigura v pokončni stoječi drži. Naslikana je od spredaj, z rahlim zasukom v stran, ko v svoji ponosni drži razkazuje lepoto svojega zunanjega blišča - in to je tudi vse, kar počne. Tizian namreč svojih ženskih modelov ni slikal ob glasbilih, pa tudi ne s čopiči ali knjigami v rokah. Lepotici na sliki La Bella je v roke raje položil rožni venec. Ženska naj moli in razkazuje svoje glavno bogastvo - lepoto zunanjega videza. Renesančni slikar žensk pač ni slikal kot izobraženih ali učenih dam.

Spolne razlike so se v slikarstvo tistega časa očitno vpisovale že zelo jasno, saj se zdi nadvse presenetliivo, da je bilo za umetnice po eni strani upodabljanje golega človeškega lika nemoralno, po drugi strani pa je bilo žensko telo prevladujoča tema v žanru akta na delih moških slikarjev. ${ }^{17}$ Umetniki so se tedaj ob upodabljanju golih ženskih figur začeli osvobajati srednjeveške zadržanosti in krščanskih moralističnih načel, tako da je spet lahko zaživela erotična umetnost. Tizian je na primer v tistem času že na veliko slikal gole ženske figure. $Z$ nekaterih je celo odstranil sramno gesto in voajerskim pogledom razkril njihova mednožja. Prav skozi njegovo slikarstvo je žanr akta doživljal svoj prvi pravi razcvet. Žensko telo je na slikah vse bolj postajalo erotični objekt, namenjen užitku moškega gledalca. Objektivizirana in sek-

17 O paradoksni situaciji v zvezi s pravili spodobnosti, po katerih so ženske, seveda iz nižjega razreda, kot goli modeli lahko pozirale moškim, same pa se niso smele pojavljati v vlogi tistih, ki bi se lahko učile risanja po golem človeškem telesu, je pisala Linda Nochlin $(2004,9)$. 
sualizirana ženska telesa so v evropskem oljnem slikarstvu prevladovala še naslednjih nekaj stoletij. ${ }^{18} \mathrm{~V}$ obdobju renesanse se je vzpostavilo tudi ključno binarno razmerje med moškim kot aktivnim umetnikom in žensko kot pasivnim modelom, ki je v žanru akta zaznamovalo večino zahodne likovne umetnosti vse do 20. stoletja. Opozicija med ženskim telesom in moškim pogledom je pozneje postala glavni predmet feministične likovne kritike.

In vendarle so že v renesansi obstajale umetnice, kakršna je bila Sofonisba Anguissola, ki se je s svojim slikarstvom postavljala nasproti prevladujočim načinom upodabljanja ženskega telesa. Čeprav je ves čas delovala bolj ali manj v skladu s konvencijami svojega časa in slikala predvsem to, kar je bilo za njen spol še sprejemljivo, je $\mathrm{v}$ portretno in še posebej avtoportretno umetnost kljub temu vpeljala nekatere nove motive. Njeno delo sicer že izhodiščno težko primerjamo $\mathrm{z}$ deli njenih moških kolegov. Pri tem ne mislim toliko na mojstrsko obvladovanje veščine in slogovno kvaliteto njenega slikarstva, kolikor na dopuščeno motiviko oziroma na to, kar ji je bilo kot ženski sploh omogočeno slikati. Njene portrete lahko vsekakor primerjamo s Tizianovimi, čeprav se moramo pri tem zavedati, da so portreti v njegovem opusu le obrobni žanr. V zvezi s Tizianovimi deli običajno mislimo na slike velikih formatov, ki se vsebinsko nanašajo na biblične in druge mitološke motive. Pri Sofonisbi Anguissola pa ne bomo našli nikakršnih dramatičnih prizorov, velikih herojskih tem ali kakršnihkoli motivov, ki bi se nanašali na golo človeško telo. Ko sem v eni od prejšnjih številk revije Ars \& Humanitas obravnavala spolno razliko $\mathrm{v}$ žanru akta, sem ob tem zapisala, naj si poskušamo zamisliti, kako bi lahko Sofonisba Anguissola kot ženska sredi 16. stoletja, ko so se gola telesa na erotičnih slikah začela prebujati v vsej dražestni seksualnosti, lahko naslikala glasbenico, ki igra na orgle in se čez ramo obrača k povsem golemu moškemu, pri čemer svoj pogled usmerja v njegovo mednožje. To si je Tizian lahko privoščil kot nekaj najbolj samoumevnega. ${ }^{19}$ Seveda se zdi absurdna že sama misel, da bi si slikarka kot

18 O ženskem telesu kot vodilni, nenehno se vračajoči temi evropskega oljnega slikarstva, je pisal John Berger v delu Načini gledanja. Prek kritike objektiziranega golega ženskega telesa je pokazal na njegovo enosmerno upodabljanje znotraj žanra, kakršen je v likovni umetnosti akt (Berger, 2008, 63).

19 Pri tem mislim na Tizianovo delo Venera $z$ orglarjem (1550), na katerem orglar svoj pogled usmerja naravnost v razkrito Venerino mednožje. Na sliki je upodobljena Venera, nezašči- 
ženska sploh drznila naslikati moški akt, kaj šele, da bi ga umestila med bele rjuhe in ga prikazala, ko si z roko v stilu sramne geste prekriva svoj ud in se smehlja proti voajerskim gledalkam. Na takšne feministične parodije je bilo treba počakati še nekaj stoletij. Prav tako si je popolnoma nemogoče zamišljati, da bi slikarka tedaj lahko upodobila glasbenico, ki bi se v svoji lezbični želji ozirala k razgaljeni renesančni lepotici. Anguissolina glasbenica je bila lahko predstavljena le kot uglajena plemkinja, ki igra na klavikord ali spinet, saj je bilo v skladu s humanističnimi ideali dobre vzgoje zaželeno, da obvladuje tudi nekaj glasbene veščine (Spacal, 2008, 134).

Preden se osredotočimo na avtoportrete s knjigo, si še poglejmo, kako je Sofonisba Anguissola na svojih lastnih podobah upodabljala samo sebe za razliko od portretov drugih žensk. Ko je portretirala ugledne dame tedanje dobe, jih je slikala podobno, kot so plemkinje v tistem času upodabljali njeni moški kolegi. Njeni portreti kraljic in aristokratinj so bili naslikani popolnoma $\mathrm{v}$ skladu $\mathrm{z}$ vsemi renesančnimi pravili, ki so veljala za portretno umetnost in idealizacijo ženske lepote. Pravzaprav je ženske tudi Sofonisba Anguissola slikala popredmeteno, saj jih je prikazovala v vsem okrasju bogatih oblačil, prek katerih je bil izpostavljen predvsem njihov status. V njenem portretnem upodabljanju plemenitih dam, ki so prek zunanjega videza izražale premožnost elitnih družin, katerim so pripadale, tako ni mogoče zaznati posebne razlike z deli moških portretistov. V zvezi z njenimi portreti plemkinj tako ne moremo govoriti o bistveno drugačnem pogledu na žensko telo. Njen pogled na bogate posameznice iz najvišjih slojev je bil dokaj podoben pogledu njenih moških kolegov. Edina razlika je morda v tem, da ženske na portretih Sofonisbe Anguissola niso bile nikdar niti najmanj erotizirane. Plemenite dame sicer tudi na portretih moških avtorjev niso bile naslikane kot erotične zapeljivke. Tudi markize, ki jih je upodabljal Tizian, niso bile predstavljene kot erotični objekti, temveč zgolj kot lepi objekti. Toda Tizian

tena s sramno gesto, ki svoje pasivno telo popolnoma predaja voajerskemu pogledu, in sicer najprej orglarja na sliki, ki gleda naravnost v njeno mednožje, prek njega pa tudi pogledu gledalca zunaj slike. O orglarju kot voajerskem posredniku med gledalcem in Venero je ob interpretaciji tega dela pisal tudi Edward Lucie-Smith v poglavju »Opazovanje Venere« svojega dela Erotičnost v umetnosti zahoda. O orglarju, ki sedi za svojim inštrumentom pri dnu postelje in obrača glavo, da bi opazoval Venerino mednožje, je zapisal: "pravzaprav služi kot neke vrste posrednik med gledalcem in erotičnim objektom: voajer, umeščen v kompozicijo, predstavlja nadomestek za voajerja, ki ne more vstopiti v sliko« (Lucie-Smith, 1973, 173). 
je poleg klasičnih naročenih portretov konkretnih oseb slikal tudi idealizirane Venere, erotične Magdalene in razne mitološke Diane ter Danaje.

Če so bile torej upodobitve premožnih renesančnih dam Sofonisbe Anguissola dokaj podobne portretom, kakršne so slikali njeni moški kolegi, pa velja poudariti, da pri avtoportretih ni bilo tako. Glavna razlika v upodabljanju ženskih figur se $\mathrm{v}$ njenem opusu kaže prav v različnem pristopu $\mathrm{k}$ slikanju portretov in avtoportretov. Medtem ko je druge ženske upodabljala v skladu s portretnimi normami tedanje dobe, je lastno figuro pogledom razkrivala nekoliko drugače. $\mathrm{V}$ nasprotju s pasivnimi figurami aristokratskih portretirank, ki so bile na slikah postavljene na ogled v vsem svojem okrasju bogatih oblek in izbranega nakita, se je slikarka upodabljala kot aktivna umetnica $\mathrm{z}$ držo resnobne dame v preprostih in dokaj skromnih oblačilih. Namesto oblek iz težkih brokatov, pošitih z zlatimi vezeninastimi vzorci, raznimi našitimi okraski in gostimi umetelnimi čipkami, kakršne so nosile plemkinje njenega družbenega stanu, so bile njene obleke videti povsem preproste, gladke in večinoma temno enobarvne. Čeprav se je upodabljala tudi kot lepa in uglajena dama, pa to na njenih slikah nikakor ni bilo izpostavljeno v prvem planu. Ne obleka ne nakit ne pričeska na njeni figuri niso bili posebej poudarjeni, kakor je bilo to značilno za estetiko renesančnih portretov plemkinj. Za razliko od dekoltejev Tizianovih lepotic, ki so poudarjali čutne obline ženskega telesa, se je umetnica slikala $\mathrm{v}$ do vratu zapetih oblekah s privzdignjenimi ovratniki. Njene obleke so krasili samo tanki robovi drobnih belih čipk na ovratniku in rokavih. Sofonisba Anguissola je samo sebe upodabljala popolnoma brez nakita ali kakršnegakoli drugega okrasja. Razlog verjetno ni bil le v tem, da bi jo nakit oviral pri slikanju. Namen njenih avtoportretov gotovo ni bil v prikazovanju same sebe kot klasične, bogato oblečene renesančne lepotice, temveč v razkrivanju povsem nove podobe izobražene renesančne ženske, ki lahko deluje kot aktivna slikarka, glasbenica ali bralka. Na Anguissolinih avtoportretih predstavljajo glavni nakit pravzaprav vsi njeni čopiči in barve, glasbila, knjige ali slike. S predstavitvijo sebe kot aktivne ženske, pri kateri je postala njena dejavnost pomembnejša od njenega zunanjega videza, je bistveno spremenila pogled na figuro ženske, ki je bila do tedaj povečini prikazovana le prek zunanje podobe. S svojimi upodobitvami je ponudila drugačno vrsto gledanja in doumevanja žensk tistega časa. To sicer velja predvsem 
za njene lastne podobe. Kot sem že omenila, je druge ženske tudi sama še vedno portretirala $v$ skladu s prevladujočimi načeli tedanjega časa. In vendarle je vsaj na področju avtoportreta s povsem novimi temami odprla pot številnim ženskim umetnicam, ki so sledile njenemu zgledu. Tako je postala pomembna vzornica mnogih slikark, ki so sebe in nato tudi druge ženske začele prikazovati v bolj subjektnih vlogah. S takšnimi upodobitvami žensk se je postopoma začela rahljati uveljavljena struktura razmerja med moškim v vlogi umetnika in s tem subjekta na eni in žensko v vlogi modela in s tem objekta na drugi strani binarne razporeditve. Čeprav so moški ženska telesa v žanru akta še vsa naslednja stoletja prikazovali dokaj enostransko, so avtorice vzporedno vendarle oblikovale alternativne načine predstavljanja ženskih figur, po katerih se je postopoma vpeljevalo drugačne načine upodabljanja ženskih teles. Tovrstni pogledi žensk s strani moških, ki so $\mathrm{v}$ umetnostnem svetu predstavljali avtoriteto in oblikovali kanon, največkrat niso bili videni in upoštevani, temveč so neredko ostali postranski ali celo popolnoma spregledani, čeprav so skozi zgodovino ves čas obstajali. Sofonisbi Anguissola velja v tem smislu pripisati mesto pionirske figure, $\mathrm{s}$ katero se je začela ne le genealogija profesionalnih ženskih slikark, temveč tudi zgodovina slikarskega pogleda žensk. Njeno delo v tradicijo zahodnega slikarstva prinaša drugačen in inovativen pogled na žensko figuro, ki ni naslikana $\mathrm{v}$ kontekstu erotičnega telesa, temveč kot izobražena dama s knjigo, glasbilom ali čopičem. Pogled prve profesionalne ženske slikarke s tem hkrati razkriva tudi novo razumevanje obdobja renesanse. Lahko bi zapisali, da se s portretnim in avtoportretnim opusom Sofonisbe Anguissola odstira zastrti vidik prezrte renesanse, ki je ostal v kulturni tradiciji predolgo spregledan in še vedno premalo raziskan.

\section{Avtoportretni motiv avtorice s knjigo}

Vrnimo se k osrednji temi pričujočega besedila, k avtoportretnim motivom avtorice s knjigo. Izpostavila sem že, da je bila Sofonisba Anguissola ena prvih slikark, ki se je upodobila s knjigo v roki. Leta 1548 se je tako narisala na mladostnem avtoportretu, ki nosi naslov Avtoportret pri šestnajstih (slika 1). 


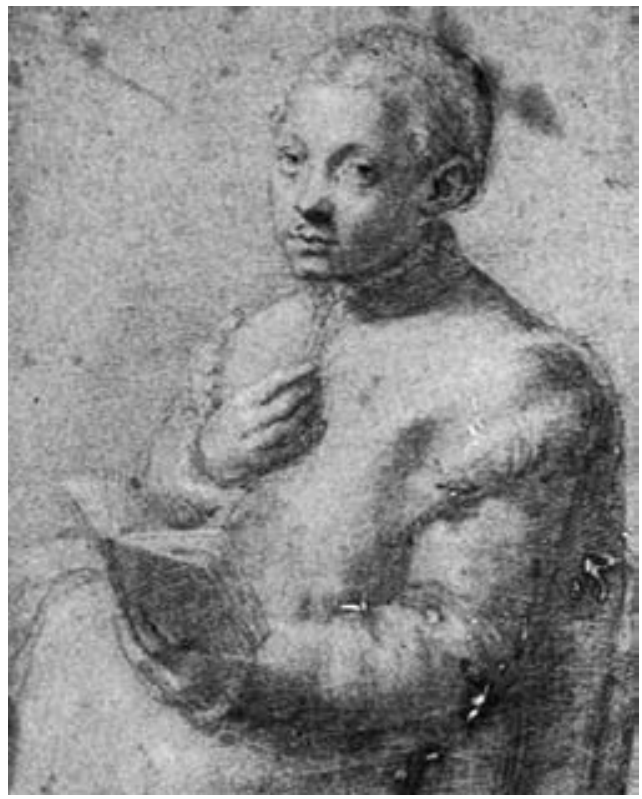

slika1: Sofonisba Anguissola, Avtoportret pri šestnajstih, 1548, črna kreda na papirju, Gabinetto dei Disegni e delle Stampe degli Uffizi, Firence vir: Borzello, 1998, 40

Mlada umetnica se je na risbi upodobila sede kot resnobna in samozavestna ženska, ki v eni roki drži odprto knjigo, z drugo pa ponosno kaže nase, na avtorico. ${ }^{20}$ Takšno avtoportretno gesto lahko po Lucu Menašeju označimo kot kazalno kretnjo. ${ }^{21} \mathrm{Na}$ tem delu je bila odprta knjiga še obrnjena

20 Sofonisba Anguissola se je na omenjenem avtoportretu upodobila kot resnobna mlada dama, kar pa ni bilo značilno za tri leta prej narisano risbo s kredo, ki nosi naslov Avtoportret s starko (1545), na kateri se je prikazala kot zelo nasmejana, ko z gesto roke kaže na resno starejšo žensko ob sebi, ki skozi naočnike gleda navzdol v knjigo. Smeh Sofonisbe Anguissola deluje za pravila ženskih portretov tistega časa presenetljivo svobodno in hkrati kaže na avtoričino rano mladost, ko je imela le trinajst let. Na naslednjem, tu obravnavanem avtoportretu, se je v skladu s pravili dostojnosti upodobila že nadvse resna, kar pomeni, da je, kot pravi Frances Borzello, osvojila lekcijo iz dostojanstva, čeprav na podobi še vedno ni poskušala skriti svojega ponosa nad lastnim umetniškim talentom. Na to kaže gesta roke, $s$ katero kaže nase (Borzello, 1998, 39).

21 Menaše je o kazalni kretnji zapisal: »Na slikarskih avtoportretih dobi poseben pomen, kadar kaže slikar na svoje prsi in nam tako ponavlja: to sem jaz! Nekaj prisrčno naivnega je v tem 
proti sami avtorici, tako da je videti, kot da bi bila namenjena branju. Šele na naslednjih delih je slikarka svoje drobne knjižice z napisi, ki so služili namesto njenega podpisa, obračala proti gledalcem.

Umetnica se je na kasnejših lastnih podobah še večkrat naslikala s knjigo $\mathrm{v}$ rokah. To so bile najpogosteje majhne knjižice, v katere je zapisala svoje ime in na ta način domiselno zaznamovala svoje avtorstvo, ki je bilo v tistem času obravnavano še precej drugače kot danes. Kot sem že omenila, so se tedaj umetniške vloge postopoma šele začele oblikovati, s tem pa tudi podpisovanje del. Sofonisba Anguissola si je za dokazovanje lastnega avtorstva na avtoportretnih delih v obdobju pred signiranjem slik očitno izbrala drobne knjižice, v katere je zabeležila lastno ime ter ob tem še kakšen podatek, morda letnico nastanka dela in svoj status. Motiv knjige na njenih lastnih podobah zato ne predstavlja toliko samega akta branja in s tem simbola učenosti kot pri kasnejših avtoricah, temveč so majhne knjižice v njenih rokah prisotne bolj kot identifikacijski predmeti, ki nadomeščajo podpis. Kot omenja Frances Borzello, si je slikarka takšno vrsto podpisovanja očitno sposodila iz portretne umetnosti tedanjega časa, ko so slikarji identiteto svojih portretirancev pogosto vpisovali na strani naslikanih knjig ali na kos papirja, ki so ga položili v roke svojim modelom, ga pritrdili na pohištvo ali dodali na ozadje slike. $\mathrm{V}$ avtoportretni umetnosti je bil tedaj takšen način podpisovanja še popolna novost. Anguissola se je na svoja dela tako podpisala vsaj trikrat. Na Avtoportretu iz leta 1552, na katerem drži čopiče v levici in kos papirja v desnici, je v ozadju slike napisala: »Sofonisba Anguissola, Cremona, je to naslikala pri svojih dvajsetih.« Dve leti kasneje pa je na doprsnem Avtoportretu (slika 2) na stran majhne knjižice z rdečimi platnicami, ki jo je odprto proti gledalcem držala v rokah, zapisala: »Sofonisba Anguissola, neporočena, samska, je to naslikala sebi, 1554« (Borzello, 1998, 49). Pri tem je zanimivo, da se je slikarki med ključnimi podatki poleg imena in letnice nastanka slike zdelo pomembno izpostaviti dejstvo, da ni poročena.

predstavljanju samega sebe in vendar si slede upodobitve, na katerih si umetnik polaga roko na prsi ali pa kaže nanje, zdaj bolj očitno in zdaj spet bolj diskretno, v nepretrgani vrsti od zgodnje renesanse do današnjih dni. Da je povsem izključena vsaka pomota, da sta predstavljalni in zato tudi avtoportretni pomen te kretnje povsem nedvoumna, je to običajno desnica, ki kaže na levo stran, na srce, torej v resnici nezaposlena levica, ki pa jo je umetnik porabil za okrepljeno poudarjanje svoje osebe« (Menaše, 1962, 130). 


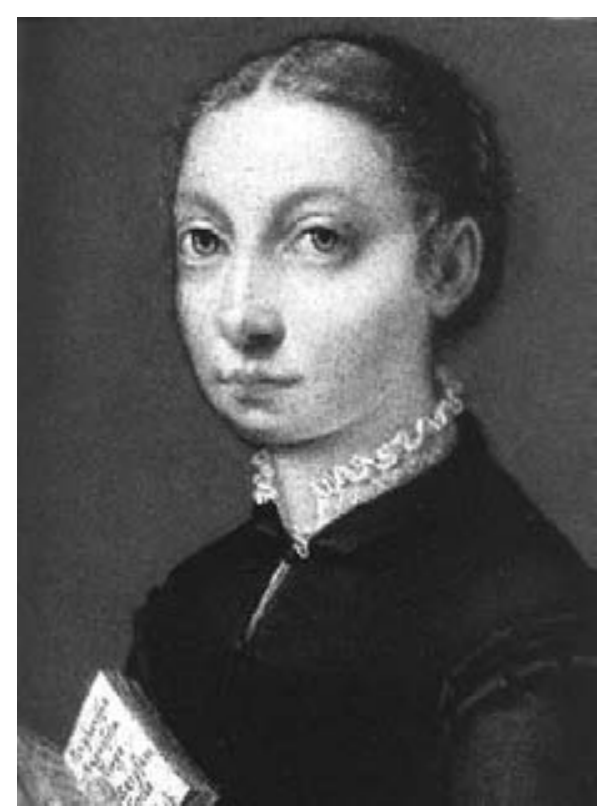

slika2: Sofonisba Anguissola, Avtoportret, 1554, Kunsthistorisches Museum, Dunaj vir: Borzello, 1998, 9

Kot ženski ji je verjetno prav takšen status omogočil, da je sploh lahko slikala. Tudi na tem Avtoportretu se je prikazala kot resnobna dama, oblečena v temno obleko in z robom drobnih belih čipk na ovratniku, zapetem do vratu. Namesto bogatega nakita in vsega okrasja, ki je bilo v tistem času obvezno za oblačila portretiranih aristokratskih dam, katerih videz je na ta način razkrival pomembnost njihovega plemiškega porekla in pripadnost določeni družini, se je Sofonisba Anguissola na lastni podobi, po zunanjem videzu sodeč, predstavila skromno, a nadvse ponosno, z majhno knjižico v rokah.

Avtoričin podpis v obliki zapisa v knjigi po mnenju Frances Borzello gledalcem zagotavlja, da gre za umetničin lastni portret in ne za portret, ki bi ga ustvaril kdo drug. Na Avtoportretu, nastalem ok. 1610 (slika 3), se je upodobila pri svojih osemdesetih letih. Na eni od svojih zadnjih lastnih podob se je prikazala kot še vedno pokončna in ponosna, ko v črni obleki vzravnano sedi naslonjena v eleganten rdeč naslanjač. $V$ eni roki si je naslikala drobno knjižico, ki jo drži skoraj zaprto, v drugi roki pa kos papirja, obrnjenega proti gledalcem, na katerem piše: »Njegovemu katoliškemu 
veličanstvu poljubljam roko, Anguissola.« Umetnica naj bi s tem izkazala spoštovanje španski kraljevi družini, pri kateri je kot portretistka delovala sredi 16. stoletja (Borzello, 1998, 24).

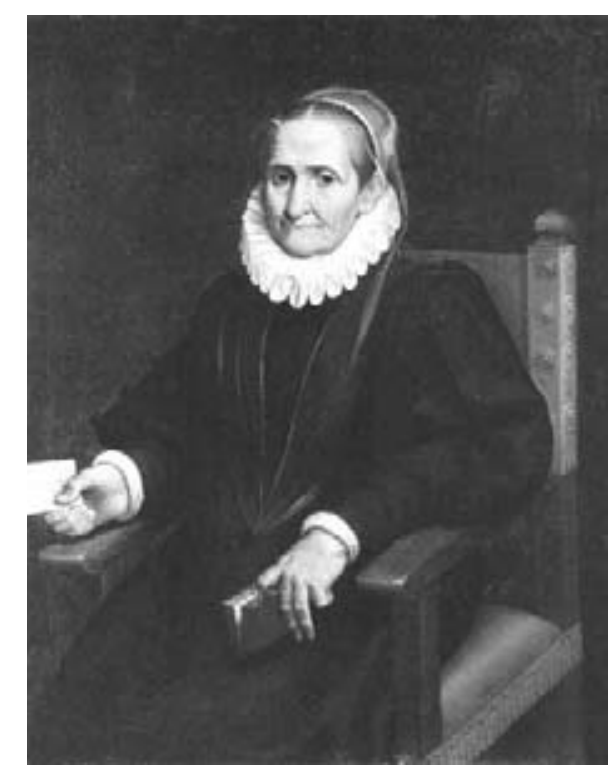

slika 3: Sofonisba Anguissola, Avtoportret, ok. 1610, Gottfried Keller Collection, Bern vir: Borzello, 1998, 25

Motiv sebe s knjigo v rokah in s kazalno kretnjo, s katero umetnica nase kaže kot na avtorico podobe, je prevzela tudi slikarkina sestra Lucia Anguissola, ki se je tako upodobila na Avtoportretu, naslikanem ok. 1557 (Borzello, 1998, 49). V času Sofonisbe Anguissola je omenjeni motiv očitno predstavljal predvsem potrditev slikarkinega avtorstva, kar je bilo za umetnice še toliko pomembnejše. Z motivom knjige $\mathrm{v}$ rokah so se slikarke šele kasneje predstavljale kot aktivne bralke in s tem učene posameznice. Za ženske, ki so težko prišle do izobrazbe, so bile takšne reprezentacije nadvse pomembne. Čeprav je bila začetnica obravnavanih motivov vsekakor že Sofonisba Anguissola, velja ob tem izpostaviti, da se v obdobju renesanse ne čopič ne knjiga kot emancipacijska atributa $\mathrm{v}$ slikarkinih rokah še nista pojavljala tako pogosto kot v kasnejših stoletjih. Kot sem že omenila, se je renesančna slikarka od vseh naštetih motivov največkrat upodobila ob knjigi. 
Med samopodobami, na katerih se je naslikala kot glasbenica, je še posebej znan njen Avtoportret ob klavikordu iz leta 1561 (slika 4).

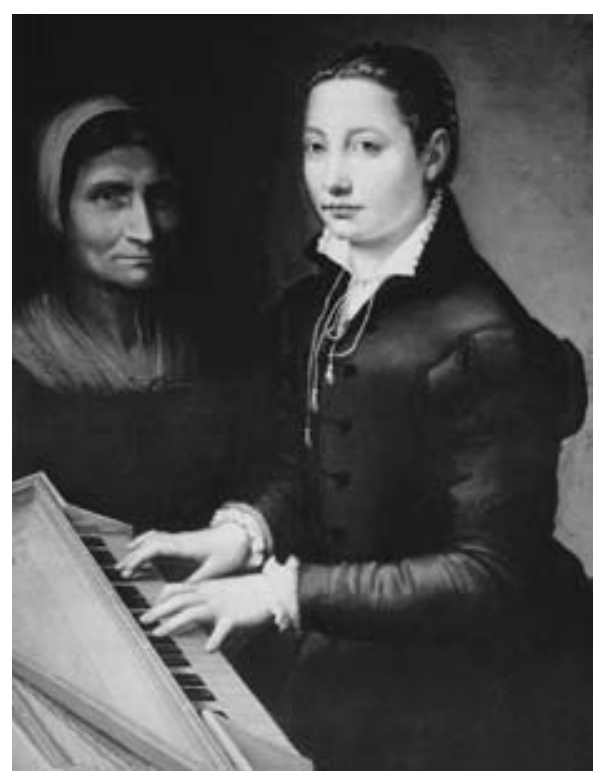

slika 4: Sofonisba Anguissola, Avtoportret ob klavikordu, 1561, Earl Spancer Collection, Althorp

vir: Borzello, 1998, 36

Kot častilka glasbene muze se je upodobila ob starem glasbilu, imenovanem spinet ali klavikord. ${ }^{22}$ Od samopodob, na katerih se je upodobila med samim slikarskim dejanjem, pa je ohranjena le ena, in sicer Avtoportret slikanja device Marije z otrokom (1556) (slika 5). ${ }^{23}$

22 Gre za eno njenih kasnejših lastnih podob in edino, naslikano v Španiji. Naslikala se je kot resnobna, skromna in uglajena mlada dama, ki v skladu s tradicijo renesančnega umetniškega ideala igra na glasbeni inštrument. Svojo glasbeno veščino je sicer predstavila že pred leti, ko se je kot mlada ženska upodobila na Avtoportretu ob klavikordu (ok. 1555-1556). $\mathrm{Na}$ Avtoportretu iz leta 1561 je ob sebi v ozadju slike naslikala tudi starejšo žensko, ki jo je najverjetneje spremljala v Španiji.

23 Avtorica se je ob slikanju religiozne tematike upodobila pred slikarskim stojalom s platnom in z vsemi slikarskimi pripomočki, ki jih je pri tem uporabljala: s čopiči, paletami, z lopaticami in vizirsko palico. Slika je izjemna tako po vsebinski kot tudi po likovni plati. Za svoj čas je nadvse inovativna, saj poleg tega, da gre za eno prvih lastnih podob, ki prikazujejo umetnico med samim slikanjem, v obliki »slike na sliki« razkriva tudi vsebino nastajajočega 


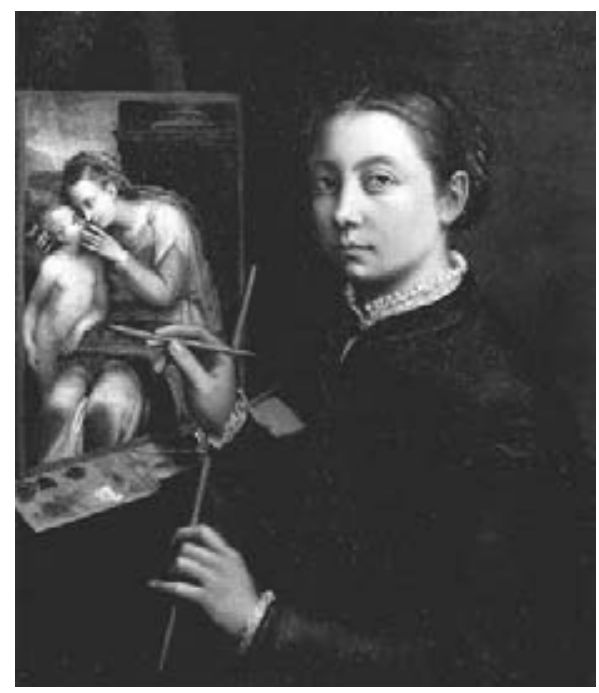

slika 5: Sofonisba Anguissola, Avtoportret slikanja device Marije z otrokom, 1556, Muzeum Zamet w Lancuice, Lancut vir: Borzello, 1998, 44

Sofonisba Anguissola je sebe slikala z vsemi omenjenimi atributi v času, ko izobrazba večini žensk še vedno ni bila dostopna. Čeprav se je v 16. stoletju za izobraževanje deklet začelo pojavljati nekoliko več možnosti, enakopravnost med spoloma, o kateri je pisal Jacob Burckhardt, zgodovinar renesanse iz 19. stoletja, še zdaleč ni bila zagotovljena. ${ }^{24}$ Humanistična spodbuda v zvezi z izobraževanjem žensk namreč ni vključevala matematike, retorike in znanosti. Zgodovinar Leonardo Bruni je še posebej svaril

dela. Podoba ni le klasičen avtoportret, na katerem bi se avtorica upodobila s čopičem v roki, kakor se je kasneje predstavljalo veliko umetnikov in umetnic, temveč je nazorno prikazala tudi temo slike, ki jo je zaključevala. Očitno se ji je zdela pomembna tudi predstavitev vsebine dela in ne le samega dejstva, da slika. Kot slikarka je lahko naslikala motiv device Marije $\mathrm{z}$ otrokom. Sicer pa iz njenega opusa, ki v glavnem obsega portrete in avtoportrete, ni znano veliko del z religiozno ali kakšno drugo mitološko tematiko.

24 Jacob Burckhardt je razumel enakost med spoloma pri izobraževanju v renesansi dokaj idealistično: "Za razumevanje višje renesančne družabnosti je bistveno spoznanje, ki ga ne smemo prezreti, da je bila žena možu enakovredna. [...] Predvsem je izobrazba žen iz višjih slojev ista kot pri možu. Italijani renesančne dobe niso imeli prav nikakega pomisleka, da ne bi svojim hčeram in sinovom nudili istega literarnega in celo filološkega pouka. Ker so v tej novoantični kulturi videli najvišji dar omikanega življenja, so jo rade volje privoščili tudi mladim dekletom « (Burckhardt, 1981, 297). 
pred študijem retorike za ženske, zato da se ne bi bile sposobne udeleževati javnih intelektualnih debat (Chadwick, 1996, 74).

Kakorkoli že, v vsakem zgodovinskem obdobju so obstajale redke posameznice, ki so izstopale zaradi svoje izobrazbe in ustvarjenih del, po katerih so kljub vsemu ostale znane. $\mathrm{V}$ zvezi $\mathrm{z}$ avtoportretnim motivom ob knjigi naj še omenim, da sta iz starejših obdobij kaligrafske umetnosti znani dve majhni lastni podobi Ester Inglis iz poznega 16. stoletja. Avtorica, ki je sicer slovela po sijajni kaligrafiji, je svoj avtoportret narisala s črnilom na začetek rokopisa. Upodobila se je, ko piše oziroma prepisuje v odprto knjigo. Petindvajset let kasneje, leta 1624, se je ponovno narisala, in sicer na zaščitnem ovoju svojega rokopisa (Borzello, 1998, 47). Pred seboj je še natančneje prikazala vse svoje pisalno orodje, peresa, stekleničko s črnilom, papir ter knjigo, iz katere je prepisovala. Tovrstne lastne podobe še posebej poudarjeno izražajo željo po predstavitvi sebe v aktivni vlogi, kar je bilo, kot sem že večkrat poudarila, za avtorice toliko večjega pomena.

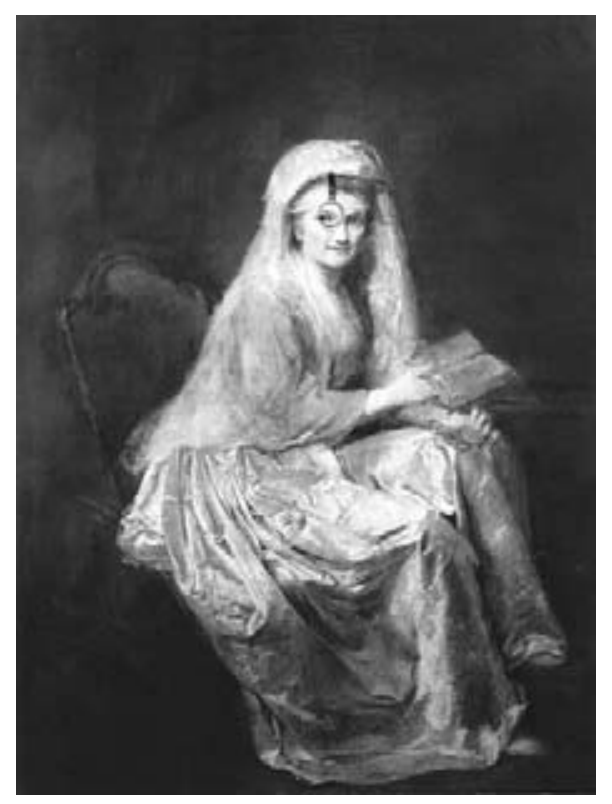

slika 6: Anna Dorothea Lisiewska-Therbusch, Avtoportret, 1779, Staatliche Museen, Berlin vir: Borzello, 1998, 73 
Enega prvih pomembnejših Avtoportretov s knjigo v rokah, ki slikarko razkriva tudi kot aktivno bralko, je leta 1779 naslikala Anna Dorothea Lisiewska-Therbusch (slika 6). Gre za precej drzen avtoportret sedeče figure, ki je na sliki celo nekoliko večja od naravne velikosti. Avtorica se je naslikala z odprto knjigo v rokah, ki jo drži rahlo naslonjeno na koleno. Na sliki je pomemben atribut izrazito viden monokel, ki še posebej poudarja avtoričino aktivno branje. Kot ponosna in resna se je tako upodobila nekaj let pred smrtjo, pri čemer je očitno, da je z držo in naslikanimi atributi želela poudariti predvsem svojo izobrazbo in uglajenost. Za razliko od podob Sofonisbe Anguissola, ki je knjige na svojih avtoportretih večinoma slikala kot identifikacijske pripomočke, v katere je lahko zabeležila svoj podpis, je knjiga v rokah Anne Dorothee Lisiewske-Therbusch naslikana kot knjiga, namenjena branju. Po mnenju Rozsike Parker in Griselde Pollock je bila v poznem 18. stoletju takšna samoprezentacija povezana $\mathrm{z}$ razvojem krožkov učenih žensk (prim. Parker in Pollock, 1987, 93; Borzello, 1998, 72; Petersen in Wilson, 1976, 48).

\section{Zaključek}

S starejšimi avtoportretnimi deli, na katerih je bila reflektirana lastna umetniška ali bralska aktivnost, se je začela genealogija umetnic kot kreativnih subjektov, ki ji lahko skozi različna zgodovinska obdobja sledimo vse do feministične umetnosti 20. stoletja. Do neke mere bi zato dela žensk iz starejših obdobij, ki razkrivajo določeno težnjo po vzpostavitvi sebe kot umetniškega subjekta, lahko primerjali z deli kasnejših feminističnih avtoric. ${ }^{25}$ Čeprav dela umetnic iz različnih zgodovinskih obdobij med seboj težko primerjamo, bi lahko kot skupno točko vseh delujočih umetnic, ki so se na lastnih podobah prikazale s knjigo, kljub temu izpostavili težnjo po vzpostavitvi lastne subjektne pozicije. Na ta način bi morda lahko začrtali

$25 \mathrm{~V}$ pričujočem besedilu sem se ob atributu knjige osredotočila predvsem na starejše avtoportrete klasičnega slikarstva. Čeprav je bil obravnavani motiv prisoten tudi v sodobni feministični umetnosti, je lahko prišel njegov emancipatorni potencial bolj do izraza prav v preteklih obdobjih, ko so bile avtorice v kontekstu izobraževanja precej bolj diskriminirane. 
vzporednice med subverzivnim učinkom avtoportretov Sofonisbe Anguissola, ki se je v renesansi upodobila s knjigo ali celo čopičem v roki, in deli feminističnih umetnic, ki so se v 20. stoletju upodobile gole in svoja telesa izpostavile tudi v kontekstu lastne seksualnosti.

Avtoportretni motiv avtorice s knjigo v rokah, ki se je predvsem na starejših delih izkazal kot izrazito emancipacijski, se je očitno pojavljal v različnih obdobjih ustvarjanja umetnic. Atribut knjige se je na lastnih podobah izkazal kot pomemben kulturni označevalec za izražanje lastne vloge bralke in s tem za vzpostavitev lastne subjektivitete. Subjektna pozicija, ki je ženske skozi zgodovino umetnosti in humanistike največkrat niso bile deležne, je bila na obravnavanih delih še posebej izpostavljena. Avtoportret je namreč kot žanr umetnicam že sam po sebi omogočil vzpostavitev subjektne drže, kar je bilo še posebej pomembno v starejših zgodovinskih obdobjih, ko ženske v umetniških praksah največkrat še niso mogle delovati enako profesionalno kot moški. Ob motivu knjige so lahko ustvarjalke lastno subjektno pozicijo na likovnih delih dodatno poudarile predvsem v obdobjih, ko ženskam izobrazba še ni bila enakovredno dostopna. Zato bi lahko zapisala, da so avtoportretne podobe umetnic s knjigo poudarjeno izpostavljale subjektne vloge avtoric. To lahko zaznamo tako pri slikarkah, ki so se upodobile v vlogah bralk, kot tudi pri tistih, ki jim je drobna knjižica ob lastni podobi služila za mesto podpisa ter s tem izpostavljenega avtorstva.

\section{LITERATURA}

Berger, J., Načini gledanja, Ljubljana, 2008.

Borzello, F., Seeing Ourselves: Women's Self-Portraits, New York, 1998.

Burckhardt, J., Renesančna kultura v Italiji, Ljubljana, 1981.

Cankar, I., Razvoj stila v dobi renesanse, Ljubljana, 1936.

Chadwick, Wh., Women, Art, and Society, London, 1996.

Lucie-Smith, E., Erotizam u umetnosti zapada, Beograd, 1973.

Menaše, L., Avtoportret v zahodnem slikarstvu, Ljubljana, 1962.

Mikuž, J., Zrcaljena podoba: ogledalo in zunanjost polja, Ljubljana, 1997. 
Nochlin, L., "Zakaj ni bilo velikih umetnic?«, Likovne besede, Teoretska priloga: Feministična teorija umetnosti, izbrani teksti, 69-70, 2004, 2-15.

Parker, R. in Pollock, G., Old Mistresses: Women, Art and Ideology, New York, 1981.

Parker, R. in Pollock, G., Framing Feminism: Art and the Women's Movement 1970-1985, Pandora, London, 1987.

Petersen, K. in Wilson, J. J., Women Artists: Recognition and Reappraisal from the Early Middle Ages to the Twentieth Century, New York, 1976.

Slatkin, W., Women Artists in History: From Antiquity to the Present, New Jersey, 1985.

Spacal, A., „Od golote Ingresove odaliske do nagote na podobi s plakata Guerrilla Girls", Ars \& Humanitas: revija za umetnost in humanistiko, II/2, 2008, 120-140.

Zuffi, S., Tizian: posebej žlahten mojster med slikarji, Slikarji, Zbirka žepnih monografij, Ljubljana, 1998. 


\title{
SELF-PORTRAIT OF AN ARTIST WITH A BOOK IN HER HAND
}

\author{
Keywords: self-portrait, book motif, subjectivity, Renaissance woman \\ painter, Sofonisba Anguissola
}

\begin{abstract}
This article considers the book as an important emancipatory motif, expressing the tendency of women self-portrait painters to present themselves as educated and accomplished, and to establish their own subjectivity. In traditional self-portraits, since the Renaissance some female artists have presented themselves as autonomous active individuals depicted painting, reading, or playing a musical instrument. In the past, the motif of the reader has symbolized female erudition, education, and sophistication. In a time when women could only rarely attend school, the use of this motif represented an important and liberating gesture. In a period when artists preferred to portray women as nude seducers rather than as learned ladies, it was all the more important that some female artists endeavored to stress the role of women as readers. Although images of women authors with a book in their hands represented a symbol of learning and wisdom, this same motif could also be used to replace a female author's signature. This is examined here with reference to the works of the Renaissance painter Sofonisba Anguissola.
\end{abstract}




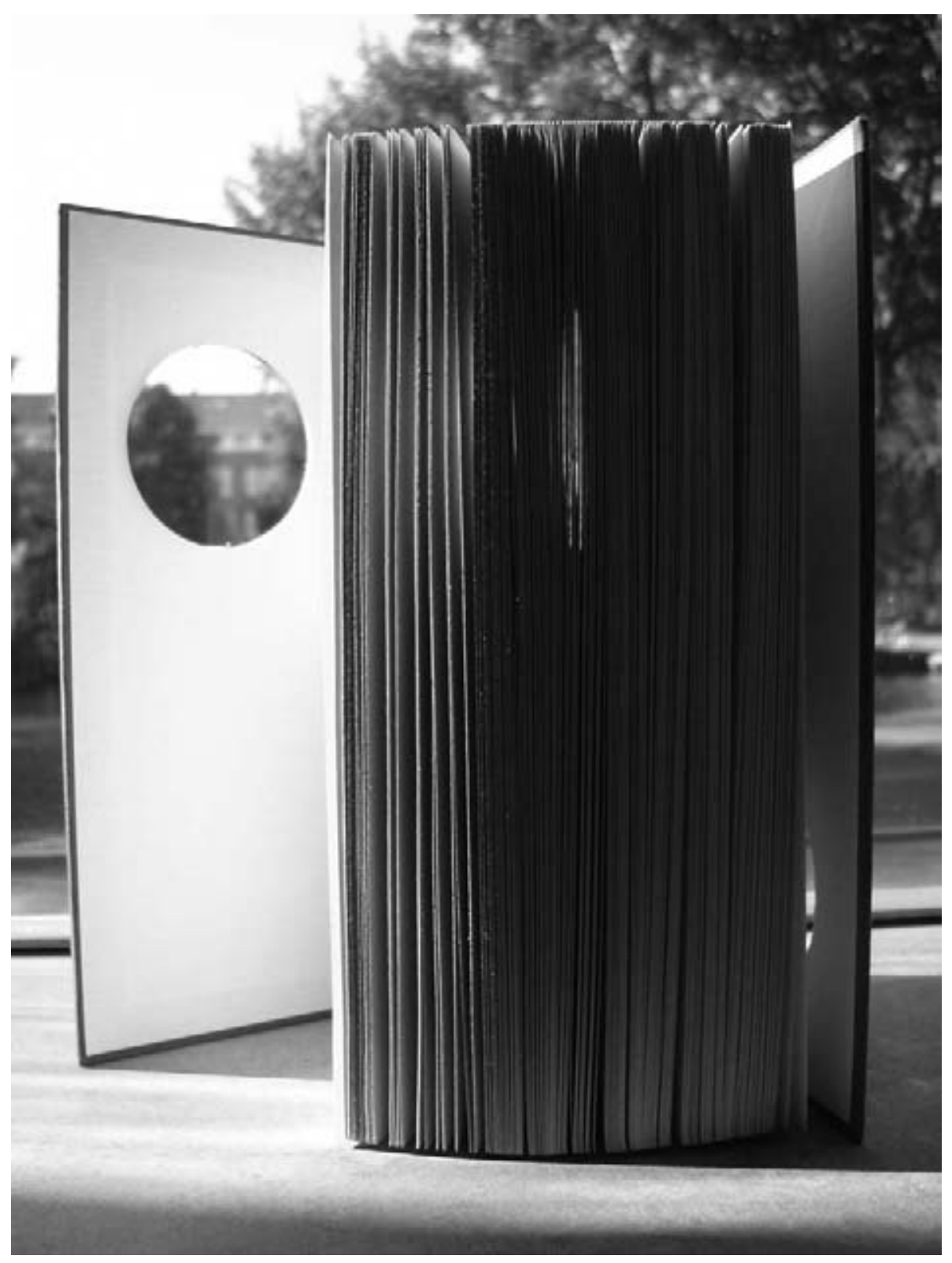

Fleur Thio: A hole book (2009)

"The fifth and last book in the collection can be seen as a statement about living in a fast world. Many people don't seem to be able to retreat and read a book: they're easily distracted and want to be able to 'change channels' every other second. By reading a book with a hole in it, we can read while keeping an eye on the outside world." 